\title{
Multilateral trade liberalization and public goods provision in a North-South trade model with nonhomothetic preferences
}

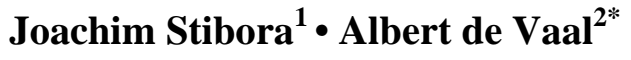 \\ ${ }^{1}$ Faculty of Arts and Social Sciences, Kingston University, Kingston, UK \\ 2 Department of Economics, Radboud University Nijmegen, Netherlands
}

\begin{abstract}
Under nonhomothetic preferences developing countries are less likely to gain from multilateral trade liberalization than developed countries. This paper shows that this relative disadvantage for developing countries changes when the effects on public good provision are taken into account. The impact it has depends on the strength of their comparative advantage in export markets. We show that a strong (weak) comparative advantage in export markets mitigates (reinforces) the relative disadvantage of multilateral trade liberalization for developing countries. Moreover, in the presence of public goods provision, the relative disadvantage for developing countries with a strong comparative advantage is further mitigated when also income differences within countries are taken into account.
\end{abstract}

Keywords: Ricardian trade model, asymmetric demand complementarities, trade liberalization, public goods, income distribution

JEL Classification Codes: F11

\section{Introduction}

When considering the effects of reciprocal trade liberalization it is important to account for income differences between and within countries. Stibora \& de Vaal (2007) show that

\footnotetext{
*Corresponding author. E-mail: a.devaal@fm.ru.nl.

Citation: Stibora, J. and de Vaal, A. (2012) Multilateral trade liberalization and public goods provision in a NorthSouth trade model with nonhomothetic preferences, Economics and Business Letters, 1(2), 27-36.
} 
developing countries (poorer countries) may witness welfare losses as the real income gains of trade liberalization will accrue to countries that produce the more advanced goods (richer countries) resulting in a terms of trade deterioration for poorer countries. This novel insight is obtained by introducing nonhomothetic preferences in their analysis; an aspect that, despite its empirical relevance, has not received much attention in trade-theoretic analyses. ${ }^{1}$

We argue that the relative disadvantage of trade liberalization may be less strong for developing countries once the effect on public good provision is taken into account. While Stibora \& de Vaal (2007) acknowledge an impact on tariff revenues, they make the standard assumption that tariff revenue is directly redistributed to households. In contrast, taxes typically find their way to households through the provision of public goods (e.g. UN Economic and Social Council, 2004). This gives rise to an effect on household welfare that is unaccounted for in their analysis: cutting import tariffs and other trade taxes will reduce the government budget, thereby endangering the provision of public goods. This may be particularly relevant for lowand middle income countries, where trade taxes still constitute a relatively important source of government revenue. Data taken from the World Bank's World Development Indicators show, for instance, that the share of taxes on international trade in total revenue in 2008 was on average $7.4 \%$ for lower middle income countries, compared to $4 \%$ for upper middle income countries and zero for high income countries. ${ }^{2}$ Furthermore, the structural characteristics of developing countries preclude a smooth transition from trade to domestic taxes (Khattry \& Rao, 2002).

In contrast to Stibora \& de Vaal (2007), this paper explicitly introduces a government that uses import tariff revenues to finance public goods. Using their set-up, with nonhomothetic preferences, we trace the implications of cutting import tariffs for public good provision and determine how this changes the overall welfare assessment of reciprocal trade liberalization. We show that particularly households in developing countries with a strong comparative advantage in export markets will be less negatively affected when tariff revenues are redistributed to households indirectly. Taking into account income differences within countries as well further reduces the relative disadvantage of these countries.

We proceed as follows. Section 2 briefly discusses the model. Section 3 considers the impact of multilateral tariff cuts on public good provision. Section 4 considers welfare effects and Section 5 concludes.

\section{North-South trade with nonhomothetic preferences ${ }^{3}$}

For our analysis we extend the Ricardian trade model with nonhomothetic preferences studied by Stibora \& de Vaal (2007) by introducing a government sector that provides public goods. We first present an overview of the model, focussing on relevant and new aspects. We assume

\footnotetext{
1 According to Deaton and Muellbauer (1983) most household budget studies support the assumption of nonhomotheticity. Hunter and Markusen (1988) and Hunter (1991) report that as much as 29 percent of world trade may be caused by nonhomogeneous preferences.

${ }^{2}$ These data are consistent with the finding by Ebrill et al. (1999) that the share of trade taxes in GDP is inversely related to the level of development. For African low-income countries, the share was 5.5\% on average in 1995, only marginally down from $6.7 \%$ in 1975 .

${ }^{3}$ A more detailed account of our modeling set-up can be found in an earlier working paper version, see Stibora \& de Vaal (2007a).
} 
that South is the developing country and North the developed country; we associate the use of an asterisk to the North.

Production and trade There exists a competitive goods sector consisting of an unbounded continuum of competitive industries, indexed by $z \in[0, \infty)$, each producing a homogeneous good also indexed by $z$. Let $a(z)$ and $a^{*}(z)$ be the unit labor requirement for good $z$ in South and North. The South has a comparative advantage in lower ranked $z$; that is $A(z) \equiv$ $a^{*}(z) / a(z)$ is continuous and strictly decreasing in $z, A^{\prime}(z)<0$. Define $\zeta(z) \equiv[\hat{a}(z) / \hat{z}-$ $\left.\hat{a}^{*}(z) / \hat{z}\right]>0$ as a measure of the strength of South's comparative advantage at $z$ (a hat denoting a percentage change). Trade flows are distorted by tariffs, where $\tau^{*}$ is one plus the uniform ad valorem import tariff imposed by South (North). Northern wages are numéraire, $w^{*}=1$. To ensure that South is the poorer of the two countries, we assume that it has an absolute disadvantage in all industries, that is, $a^{*}(z)<a(z)$ for all $z$. This ensures that in equilibrium $w<1$.

Production is determined by producer prices which differ from consumer prices by destination-based value-added-taxes, $\iota$ and $\iota^{*}$. The local price $p\left(p^{*}\right)$ of good $z$ is:

$$
p(z)=\min \left\{w a(z) \iota, \tau a^{*}(z) \iota\right\} \quad \text { and } p^{*}(z)=\min \left\{a^{*}(z) \iota^{*}, \tau^{*} w a(z) \iota^{*}\right\} .
$$

South produces good $z$ if $w \leq \tau A(z)$ and North produces $z$ if $A(z) \leq \tau^{*} w$. The borderline commodities between South's (North's) non-traded commodities and North's (South's) exports are denoted by $\tilde{z}=A^{-1}(w / \tau)$ and $\tilde{z}^{*}=A^{-1}\left(\tau^{*} w\right)$, where $\tilde{z}^{*}<\tilde{z}$. Hence, South produces commodities $z \in[0, \tilde{z}]$, of which $z \in\left[0, \tilde{z}^{*}\right]$ are exclusively produced in South and exported. North produces goods $z \in\left[\tilde{z}^{*}, \infty\right)$, exporting the higher-indexed goods $z \in[\widetilde{z}, \infty)$. Goods $z \in\left(\tilde{z}^{*}, \tilde{z}\right)$ define an intermediate range of goods that both countries produce and do not trade.

Nonhomothetic demand There are $N\left(N^{*}\right)$ southern (northern) households with identical tastes. Different effective labor endowments generate an income distribution (Matsuyama, 2000). Goods come in discrete units and households' demand is satiated after consuming one unit, indicated by the consumption indicator $x(z)=\{0,1\}$. Making appropriate assumptions to ensure that the order in which households purchase goods is the same as the order of comparative advantage (see Stibora \& de Vaal, 2007), households purchase lower-indexed goods first and extend consumption to higher-indexed goods only when their income increases, leading to higher utility. Hence, South (North) has a comparative advantage in the production of lower-ranked (higher-ranked) goods which are consumed by poorer (richer) households.

The utility of households also depends on the availability of a public good $G$ and is defined in general form as

$$
V_{j}=V_{j}\left(G ; \int_{0}^{\infty} x(z) d z\right)
$$

An analogous expression holds for northern households. We assume that marginal utility of the public good $G$ is positive but decreasing. 
Let $h\left(h^{*}\right)$ denote the skill level of a southern (northern) household. We will consider two specific skill distributions. The homogeneous population case (HOM) assumes that all households are endowed with one unit of effective labor $\left(h=h^{*}=1\right)$ and everyone can afford to spend their last unit of income on the higher-indexed goods North produces (see below). The heterogeneous population case (HET) assumes that in both countries part of the population has a skill level $h_{L}$ and $h_{L}^{*}$, which in equilibrium deprives them of purchasing the higher-indexed northern goods. Without loss of generality, we assume that this applies to half of the population in each country. The other half of the population has skill level $\left(h_{H}, h_{H}^{*}\right)$, allowing them to spend their last unit of income on northern goods. The main difference between the two skill distributions considered is that HET permits income differences within countries.

Define

$$
E(z) \equiv \int_{0}^{z} p(s) d s=\int_{0}^{z} \min \left\{w a(z) \iota, \tau a^{*}(z) \iota\right\} d s
$$

as the minimum income a southern household requires to consume $z$. The highest-indexed commodity $n$ a southern household is able to consume is derived from

$$
E(n)=w h_{j}
$$

with $h_{j}$ denoting the relevant skill level $\left(h, h_{L}\right.$ or $\left.h_{H}\right)$. An analogous condition applies to a northern household, determining $n^{*}$ as the highest ranked good it can afford. Note therefore that the total number of industries in our model is endogenously determined by the tariff rates set and the income levels of consumers. For HOM it holds that in equilibrium $\tilde{z}^{*}<\tilde{z}<n<n^{*}$, since northern households are richer than southern households $\left(w<1\right.$ and $\left.h=h^{*}=1\right)$. For HET there are $N / 2$ households who do not import in equilibrium $\left(n_{L}<\tilde{z}\right)$, while in North there are $N^{*} / 2$ households who only import $\left(n_{L}^{*}<\tilde{z}^{*}\right)$.

To distinguish the two specific skill distributions, we use the notation $\delta_{i}=\{0,1 / 2\}$, $n_{i}=\left\{n, n_{H}\right\}$ and $h_{i}^{(*)}=\left\{1, h_{L}^{(*)}+h_{H}^{(*)}\right\}$ for $i=\{$ HOM, HET $\}$ below.

Government budget The public good is characterized by jointness in consumption and nonexcludability. It is financed by revenues collected from a value added tax $\iota$ and an import tariff $\tau$. All taxes are set and collected by the government which also hires labor to produce public goods. Requiring balanced government budgets, we get:

$$
\begin{gathered}
w a_{g} G=\left(1-\delta_{i}\right) N\left[(\tau-1) \int_{\tilde{z}}^{n_{i}} a^{*}(s) d s+w h_{i} \frac{\iota-1}{\iota}\right] \\
a_{g}^{*} G^{*}=\left(1-\delta_{i}\right) N^{*}\left[\left(\tau^{*}-1\right)\left(\frac{2 \delta_{i} h_{L}^{*}}{\iota^{*} \tau^{*}}+\int_{0}^{\tilde{z}^{*}} w a(s) d s\right)+h_{i}^{*} \frac{\iota^{*}-1}{\iota^{*}}\right],
\end{gathered}
$$

with $a_{g}\left(a_{g}^{*}\right)$ the unit labor requirement. The first and second terms on the right-hand-side of these expressions represent revenue from import tariff and value added tax, respectively. 
In the southern government budget, (5), there are positive import tariff revenues as long as there are households that import, that is when $n>\tilde{z}(\mathrm{HOM})$ and $n_{H}>\tilde{z}$ (HET); this is assumed to hold in equilibrium. In the northern government budget, (6), import tariff revenues are always positive since northern households always import (some of) the lower-indexed goods produced by South, $\int_{0}^{\tilde{z}^{*}} w a(s) d s>0$. Income differences within countries affect total northern revenue from import tariffs: in the HOM case all households contribute equally to tariff revenue; in the HET case a poor household contributes $\left(\tau^{*}-1\right) h_{L}^{*} /\left(\iota^{*} \tau^{*}\right)$ to tariff revenue while a rich household's contribution amounts to $\left(\tau^{*}-1\right) \cdot \int_{0}^{\tilde{z}^{*}} w a(s) d s$.

Equilibrium properties Trade equilibrium requires equal values of exports and imports. This implies, from South's point of view,

$$
\frac{N^{*}}{\tau^{*} \iota^{*}}\left[\frac{\delta_{i}}{1-\delta_{i}} \frac{1}{w} h_{L}^{*}+\tau^{*} \iota^{*} \int_{0}^{\tilde{z}^{*}} a(s) d s\right]=\frac{N}{\tau \iota}\left[h_{i}-2 \delta_{i} h_{L}-\iota \int_{0}^{\tilde{z}} a(s) d s\right]
$$

This reveals an important difference in the way the trade balance is affected by southern wages $(w)$ and its dependence on northern policy parameters, depending on the assumed skill distributions (HOM, HET).

In the homogeneous population case, $\delta_{H O M}=\{0\}, w$ does not appear directly in the trade balance condition (7) and it exerts only an indirect impact through its relation to $\tilde{z}$ and $\tilde{z}^{*}$. With all households rich enough to afford the higher-ranked northern goods, changes in purchasing power only affect consumption of northern goods. With trade initially balanced, no wage adjustment is required to restore balanced trade since there is no shift in spending from northern goods to southern goods. A similar reasoning explains why in the homogeneous population case only southern policy parameters are relevant for trade balance equilibrium. The real income gains arising, e.g., from lower southern tariffs, are spent on northern goods. This requires South to increase its range of production to preserve trade balance. When northern tariffs fall, the gains accrue to northern households. They will expand their consumption basket towards the higher-ranked goods produced in North, requiring no trade balance adjustments.

In contrast, in the heterogeneous case, $\delta_{H E T}=\{1 / 2\}$, the trade balance condition will depend on southern wages and on northern policy parameters. This is due to the fact that part of North's population only buys southern goods. ${ }^{4}$

4 The trade balance condition holds if $w$ is sufficiently small in equilibrium. The asymmetry in these trade balance effects disappears when tariff revenues are redistributed back to households, see Stibora \& de Vaal (2007). 


\section{Trade liberalization and public good provision}

We next want to evaluate the effects of multilateral tariff reductions. To this end, we define $d \tau_{M} / \tau_{M}$ as the proportional change in both the northern and southern tariff rates, i.e. $d \tau / \tau=$ $d \tau^{*} / \tau^{*} \equiv d \tau_{M} / \tau_{M}<0$. The impact of multilateral trade liberalization on public goods provision in South and North then becomes: ${ }^{5}$

$$
\begin{aligned}
& w a_{g} G \frac{\tilde{G}}{\hat{\tau}_{M}}=\left(1-\delta_{i}\right) N \int_{\tilde{z}}^{n_{i}} a^{*}(s) d s \\
& +\frac{\left(1-\delta_{i}\right)}{D_{i}}(\tau-1) N N^{*} w a(\tilde{z}) \tilde{z}\left\{\zeta\left(\tilde{z}^{*}\right)\left(\int_{0}^{\tilde{z}^{*}} a(s) d s-2 \delta_{i} \int_{0}^{n_{L}^{*}} a(s) d s\right)-2 a\left(\tilde{z}^{*}\right) \tilde{z}^{*}\right\} \\
& a_{g}^{*} G^{*} \frac{\tilde{G}^{*}}{\hat{\tau}_{M}}=\left(1-\delta_{i}\right) N^{*} w\left[\tau^{*} \int_{0}^{\tilde{z}^{*}} a(s) d s+2 \delta_{i} \int_{0}^{n_{L}^{*}} a(s) d s\right] \\
& +\frac{\left(\tau^{*}-1\right) N^{*} w}{D_{i}}\left\{\begin{array}{c}
\left(1-\delta_{i}\right)\left(N^{*} \tau \zeta(\tilde{z}) \int_{0}^{\tilde{z}^{*}} a(s) d s+N a(\tilde{z}) \tilde{z}-2 \delta_{i} N^{*} \tau \zeta(\tilde{z}) \frac{a\left(\tilde{z}^{*}\right) \tilde{z}^{*}}{\zeta\left(\tilde{z}^{*}\right)}\right) \\
\times\left(\zeta\left(\tilde{z}^{*}\right) \int_{0}^{\tilde{z}^{*}} a(s) d s-2 a\left(\tilde{z}^{*}\right) \tilde{z}^{*}\right) \\
+\delta_{i} \frac{a\left(\tilde{z}^{*}\right) \tilde{z}^{*}}{\zeta\left(\tilde{z}^{*}\right)} \zeta(\tilde{z}) N^{*} \tau\left[\zeta\left(\tilde{z}^{*}\right)\left(\int_{0}^{\tilde{z}^{*}} a(s) d s-\int_{0}^{n_{L}^{*}} a(s) d s\right)-2 a\left(\tilde{z}^{*}\right) \tilde{z}^{*}\right]
\end{array}\right\}
\end{aligned}
$$

where $D_{i}>0$ for $i=\{$ HOM, HET $\}$. Recall, $\zeta(z) \equiv\left[\hat{a}(z) / \hat{z}-\hat{a}^{*}(z) / \hat{z}\right]>0$ measures South's comparative advantage at $z$. Equations (8) and (9) indicate that the impact on public good provision has two effects. The first term in both expressions represents the price effect caused by the change in tariff revenue and the second term represents a volume effect.

The price effect is unambiguously negative in both countries since tariffs go down $\left(\hat{\tau}_{M}<0\right)$. The magnitude of the price effect depends on the skill distribution case considered with the price effect smaller in magnitude in the HET case, $\delta_{H E T}=\{1 / 2\}$, compared to HOM, $\delta_{H O M}=$ $\{0\}$. When considering a nondegenerate skill distribution, the price effect is substantially stronger in South than in North since in North even poor households import from South, while only half of the southern households can afford to import northern goods. As long as the income of the poorest southern households is insufficient to afford northern import goods, this result generalizes to all conceivable income distributions within countries.

The volume effect of trade liberalization is ambiguous for both countries and its sign depends on the effect on South's range of imported goods,

$$
\frac{d n_{i}-d \tilde{z}}{\hat{\tau}_{M}}>(<) 0 \Leftrightarrow\left[\zeta\left(\tilde{z}^{*}\right)\left(\int_{0}^{\tilde{z}^{*}} a(s) d s-2 \delta_{i} \int_{0}^{n_{L}^{*}} a(s) d s\right)-2 a\left(\tilde{z}^{*}\right) \tilde{z}^{*}\right]>(<) 0 .
$$

\footnotetext{
${ }^{5}$ The derivations of the comparative statics effects we discuss are available upon request.
} 
If South's import range increases (decreases) the volume effect is positive (negative) in the HOM case $\left(\delta_{H O M}=\{0\}\right)$ for both countries. For the HET case $\left(\delta_{H E T}=\{1 / 2\}\right)$, an additional condition needs to be satisfied which however is also related to the strength of South's comparative advantage at $\tilde{z}^{*}, \zeta\left(\tilde{z}^{*}\right)$. As long as South has a comparative advantage in its marginal export good $\tilde{z}^{*}$, South's terms of trade must deteriorate to restore trade balance. When $\zeta\left(\tilde{z}^{*}\right)$ is sufficiently large to ensure that the right hand side of equation (10) is positive, the deterioration of the terms of trade is so large that southern households reduce the range of goods they are able to consume, $d n<0$, while increasing the range of goods South produces, $d \tilde{z}>0$.

For both HOM and HET, it thus follows that the stronger the comparative advantage at $\tilde{z}^{*}$, the more likely the volume effect will be negative. The effect is more pronounced for North, since the real income effects in both countries primarily affect goods that North exports. If, instead, $\zeta\left(\tilde{z}^{*}\right)$ 's value is sufficiently low to ensure that South's import range increases, this will be more beneficial for North's public good.

Overall, the effect of trade liberalization on the provision of public goods is negative for both South and North if $\zeta\left(\tilde{z}^{*}\right)$ is sufficiently large, ceteris paribus. On account of a less negative volume effect, the impact on South is less detrimental though. This advantage is amplified by a less negative price effect in case household incomes differ within countries. When the strength of South's comparative advantage at $\tilde{z}^{*}$ is smaller, the overall effect on public good provision becomes ambiguous. Moreover, the relative advantage of the volume effect shifts to North, while HET remains favorable for South. These results emanate from the biased spending effect of any real income change on northern goods. Furthermore, if part of society does not import, public goods provision will be less affected by a decrease in trade, for tariff revenues constitute a smaller part in the overall government budget.

\section{Welfare effects}

We next consider the welfare effects of multilateral tariff reductions in the presence of public goods. The welfare effect of multilateral tariff reductions on the range of goods a southern household is able to consume can be expressed by

$$
\frac{a^{*}\left(n_{i}\right) d n_{i}}{\hat{\tau}_{M}}=\zeta(\tilde{z}) N^{*} \tau \int_{\tilde{z}}^{n_{i}} a^{*}(s) d s\left[\frac{\zeta\left(\tilde{z}^{*}\right)\left(\int_{0}^{\tilde{z}^{*}} a(s) d s-2 \delta_{i} \int_{0}^{n_{L}^{*}} a(s) d s\right)-2 a\left(\tilde{z}^{*}\right) \tilde{z}^{*}}{D_{i}}\right],
$$

where $n_{i}=n$ in case of HOM and $n_{i}=n_{H}$ in case of HET. The sign of the welfare effect for rich southern households brought about by the change in the range of competitive goods consumption is ambiguous and depends on the sign of (10), which refers to the change in the trade volume. Poor southern households are not directly affected by this trade policy since they do not exchange goods that are trade internationally, $a\left(n_{L}\right) d n_{L}=0$.

By contrast, rich and poor households in North unambiguously gain from reciprocal tariff cuts: 


$$
\begin{aligned}
& \frac{a^{*}\left(n_{i}^{*}\right) d n_{i}^{*}}{\hat{\tau}_{M}}=-\tau^{*} \zeta\left(\tilde{z}^{*}\right) \int_{0}^{\tilde{z}^{*}} w a(s) d s\left[\frac{\zeta(\tilde{z}) N^{*} \tau\left(\int_{0}^{\tilde{z}^{*}} a(s) d s+2 \delta_{i} \int_{0}^{n_{L}^{*}} a(s) d s\right)+2 N a(\tilde{z}) \tilde{z}}{D_{i}}\right] \\
& \frac{a^{*}\left(n_{L}^{*}\right) d n_{L}^{*}}{\hat{\tau}_{M}}=-\zeta\left(\tilde{z}^{*}\right) \int_{0}^{n_{L}^{*}} a(s) d s\left[\frac{\zeta(\tilde{z}) N^{*} \tau\left(\int_{0}^{\tilde{z}^{*}} a(s) d s+2 \delta_{i} \int_{0}^{n_{L}^{*}} a(s) d s\right)+2 N a(\tilde{z}) \tilde{z}}{D_{i}}\right],
\end{aligned}
$$

where $n_{i}^{*}=n^{*}$ for HOM and $n_{i}^{*}=n_{H}^{*}$ for HET.

These results on competitive goods consumption are qualitatively the same as in Stibora \& de Vaal (2007). When combined with the welfare effects on account of public goods provision, and irrespective of how we weigh the two arguments in the utility function (2), we can conclude that when trade decreases (equation (10) greater than zero), the inclusion of public goods improves the relative welfare position of southern households upon multilateral trade liberalization. The disadvantage of southern households on account of private good consumption - southern households lose while northern households gain - is mitigated by the more negative effect on public good provision for North. This is even more pronounced in the heterogeneous population case. If, on the other hand, trade increases upon liberalization (equation (10) smaller than zero), the inclusion of public goods deteriorates the relative welfare position of southern households. Although southern households also gain from competitive goods consumption, now their relative disadvantage in comparison to northern households is amplified by the effect on public goods provision.

These results arise because redistributing tariff revenue through public good provision moderates the effects of trade liberalization differently than rebating tariff revenues directly to households. The latter case implies that households effectively pay tariff exclusive prices, so that the rebates can be seen as a lump-sum subsidy to households that import. This is not the case when tariff revenue is redistributed through financing public goods, implying a 'subsidy' to all households paid by households who import. This primarily matters when not all households within a country have the same income level.

\section{Concluding remarks}

In general, multilateral tariff reductions are considered to be beneficial for all parties involved as it enhances economic efficiency. This perception is not validated when preferences are nonhomothetic, in which case reciprocal trade liberalizations are likely to deteriorate the terms of trade for developing countries (Stibora \& de Vaal, 2007). This paper shows that the relative disadvantage for developing countries changes when the effects on public good provision are also taken into account. The crucial aspect is whether or not trade increases when tariff rates are cut multilaterally. If developing countries have a strong (weak) comparative advantage in export markets, trade will decrease (increase) and the relative disadvantage of multilateral trade liberalization for developing countries is mitigated (reinforced) by the inclusion of public good provision. We also show that the income distribution within countries matters, as it reduces the relative disadvantage of developing countries with a strong comparative advantage even further. 
These results have been obtained in a framework that has made the same assumptions regarding technology and preferences as in Stibora \& de Vaal (2007). This has served the purpose well of determining how it matters when the budgetary consequences of import tariffs cuts affect households through the provision of public goods rather than through direct redistribution schemes. Clearly, to obtain a more complete picture of how trade liberalization affects public goods provision and welfare when preferences are nonhomothetic requires close scrutiny of some of the assumptions made. For instance, the analysis takes an extreme view on preferences for competitive goods by excluding substitution effects altogether. Other forms of nonhomothetic preferences, for example as proposed by Fajgelbaum et al. (2011), could be considered to see how robust our results are. Furthermore, we have not made explicit how public goods and competitive goods consumption exactly combine to generate household utility. Though, as argued, this is immaterial for the comparison with Stibora and de Vaal (2007), it would affect the overall welfare assessment.

The analysis we offer could also be extended. One extension would be to allow government to take measures to compensate the lost revenue from import taxation. Clearly, this will give rise to a trade-off in terms of welfare: budget-neutralizing schemes are good for welfare because of their effect on public goods provision, while a negative welfare effect arises because higher taxes imply lower real income. In contrast to standard analyses assuming homothetic preferences, we would expect that especially the poor in developing countries will be negatively affected by (the introduction of) such schemes. Consuming a much lower share of their income on imported goods than rich people, lower income groups hardly benefit from income tariff cuts yet fully share the burden of increased domestic taxation. From this perspective, it would also be interesting to find out how these effects will depend on the particular type of tax instrument being used (for instance, value-added-taxes versus direct income taxation) and on the particular way such instruments would be implemented (for instance, linear versus progressive taxation).

Our framework could also be used to analyse how nonhomothetic preferences would matter for the outcomes of the extensive literature discussing the (welfare) effects of piecemeal tariff reforms, see Anderson and Neary (2007) for a survey. The contributions in this literature appear to focus exclusively on the efficiency effects of tariff changes: tariff cuts are offset by increases in consumption taxes to secure the efficiency gains from trade liberalization while preserving public revenue for a small open economy. Our paper could add to this literature by offering a framework that also allows for a focus on distributional issues. Furthermore, by including nonhomothetic preferences, we employ a framework that assigns a central role to income differences between and within countries, an issue that is not addressed in this particular literature at all, despite its focus on developing countries.

Finally, the theory could be linked with the empirical literature, which would however require more than two countries to be considered. Until recently, the main obstacle to this extension has been the lack to rank goods across countries according to comparative advantage. As shown by Costinot (2009), this can be solved by the powerful concept of logsupermodularity and we leave this extension for future research.

Acknowledgements. We thank Marcia Schafgans and an anonymous referee for their useful comments and suggestions. 


\section{References}

Anderson, J.E. and Neary, J. P. (2007) Welfare versus market access: the implications of tariff structure for tariff reform, Journal of International Economics, 71, 187-205.

Costinot, A. (2009) An elementary theory of comparative advantage, Econometrica, 77, 11651192.

Deaton, A. and Muellbauer, J. (1983) Economics and consumer behaviour, Cambridge University Press: New York.

Ebrill, L, Stotsky, J. and Gropp, R. (1999) Revenue implications of trade liberalization, IMF Occasional Paper No 180, International Monetary Fund, Washington DC.

Fajgelbaum , P.D., G.M. Grossman and E. Helpman (2011) Income distribution, product quality, and international trade, Journal of Political Economy, 119, 721-765.

Hunter, L.C. (1991) The contribution of nonhomothetic preferences to trade, Journal of International Economics, 30, 345-358.

Hunter, L.C. and Markusen, J.R. (1988) Per-capita income as a determinant of trade, in: R. Feenstra (ed.): Empirical methods for international trade, Cambridge, Mass.: MIT Press, 89-109.

Khattry, B. and Rao, J.M. (2002) Fiscal faux pas?: an analysis of the revenue implications of trade liberalization, World Development, 30, 1431-1444.

Matsuyama, K. (2000) A Ricardian model with a continuum of goods under nonhomothetic preferences: demand complementarities, income distribution and North-South trade, Journal of Political Economy, 108, 1093-1120.

Stibora, J. and de Vaal, A. (2007) Trade policy in a Ricardian model with a continuum of goods under nonhomothetic preferences, Journal of Development Economics, 84, 350-377.

Stibora, J. and de Vaal, A. (2007a) Trade liberalization and its fiscal implications in a NorthSouth trade model, Economics discussion paper 2007/01, Kingston University, Faculty of Arts \& Social Sciences, School of Economics, February 2007: http://eprints.kingston.ac.uk/1380/

UN Economic and Social Council (2004) Basic data on government expenditure and taxation, Report of the secretariat for the Committee of Experts on Public Administration, E/C.16/2004/7, United Nations, New York.

World Bank (2011) World Development Indicators, http://data.worldbank.org/indicator: Taxes on international trade (\% of revenue). 